\title{
e.Med - das Wissens- und Servicepaket für Ärzte
}

\begin{abstract}
Wer sich heute umfassend informieren will, wird kaum in mehrbändigen Nachschlagewerken suchen. Viel einfacher ist die Recherche im Web. Das gilt nicht nur für den privaten Bereich, sondern auch und gerade für den beruflichen Alltag. Besonders einfach funktioniert das via e.Med, dem Wissens- und Servicepaketfür Ärzte, das gleich mehrere nützliche Angebote miteinander verknüpft.
\end{abstract}

Fortbilden, CME-Punkte sammeln, recherchieren, Expertenbeziehungsweise Kollegenrat einholen, eine eigene Homepage erstellen, berufspolitische Informationen abrufen - das alles und noch mehr ermöglicht „e.Med“, ein Online-Paket, das mit seinen vielfältigen Komponenten weit mehr bietet als gewöhnliche Portale. e.Med eröffnet Ärzten einen umfassenden Zugang zur digitalen Welt der Medizin. Dabei sind alle Bausteine so konzipiert, dass sie Ärzte in ihrem beruflichen Alltag bestmöglich unterstützen. Alles, was für das Berufsleben hilfreich und notwendig ist, steht mit einem Universalzugang zur Verfügung:

- Die e.Akademie bietet die Möglichkeit, aus über 500 zum Teil interaktiv gestalteten, zertifizierten Fortbildungsmodulen zu wählen und CME-Punkte zu sammeln.

- In der e.Bibliothek kann in über 400 medizinischen Fachzeitschriften und Magazinen recherchiert werden. Das gilt auch für die medizinischen Zeitschriften auf SpringerLink, einer der weltweit größten Online-Bibliotheken, wo mithilfe der Volltextsuche relevante wissenschaftliche Veröffentlichungen aus der internationalen Literatur zu finden sind.

- e.News garantiert täglich aktuelle Nachrichten aus Medizin und Gesundheitspolitik. Hier finden sich journalistisch auf- bereitete Beiträge, Kongressberichte, Interviews und Videos sowie alle Inhalte aus den Fach- und Themen-Newslettern der unterschiedlichen Fachgebiete.

- e.Praxis ist der erste Website-Baukasten speziell für Ärzte. Ohne Programmierkenntnisse lässt sich einfach und schnell der eigene Internetauftritt erstellen. Für die digitale Patientenkommunikation werden darüber hinaus täglich qualitätsgesicherte Medizin-News zur Verfügung gestellt.

Als Ergänzung zum Online-Paket können e.Med-Abonnenten ohne Aufpreis eine von 80 Print-Zeitschriften auswählen. Dieses Angebot ist optional. Noch interessanter ist, dass die Komponenten, die über den e.Med-Zugang verfügbar sind, kontinuierlich weiterentwickelt werden. Zusatzkosten entstehen dadurch nicht - der Preis bleibt.

Heute schon ist e.Med das komplexeste Online-Angebot in der deutschsprachigen Medizin. Eine ausführliche Darstellung der vielen Funktionalitäten und Vorteile der einzelnen Bausteine lesen Sie in anschließender Serie. Den Anfang macht die e.Akademie.

\section{Steigen Sie ein bei e.Med und gewinnen Sie einen BMW 320d Luxury Line Limousine}

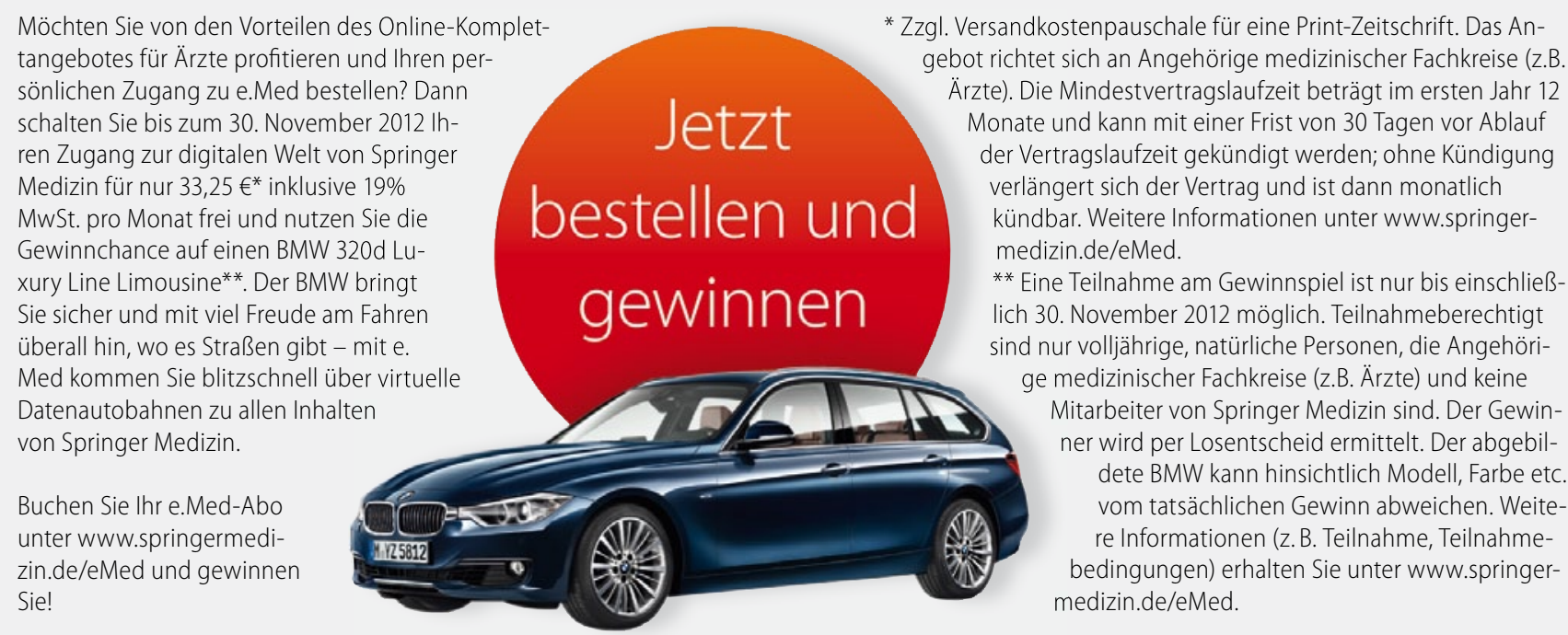

